http://dx.doi.org/10.30681/23588403v13i0203

\title{
PROCESSOS DE ENSINO E APRENDIZAGEM (OU NÃO) DA LETRA CURSIVA NO CONTEXTO ESCOLAR
}

Data de recebimento: $19 / 03 / 2020$

Aceite: 12/05/2020

\author{
Vanessa Rafaela Trierweiler CARGNIN (UERGS) ${ }^{1}$ \\ Veronice Camargo da SILVA (UERGS) ${ }^{2}$
}

Resumo: As concepções divergentes que ocorrem, atualmente, a respeito do ensino e aprendizagem (ou não) da letra cursiva, motivaram a proposição da presente discussão, a fim de compreender como os processos de alfabetização e letramentos acontecem, especificamente, no uso de todos os tipos de letras no contexto escolar. A pesquisa foi aplicada através de questionários a professores da Rede Municipal de Ensino de Novo Hamburgo/RS e, para a análise dos dados produzidos, utilizou-se a perspectiva bakhtiana sobre o ensino da língua de forma reflexiva, a legislação e os documentos orientadores para embasar a defesa da garantia do processo de alfabetização no uso social da escrita e leitura.

Palavras-chave: Letra cursiva. Alfabetização. Bakhtin. BNCC.

\begin{abstract}
The divergent conceptions that currently occur regarding of teaching and learning (or not) cursive letters, motivated to propose this discussion, in order to understand how literacy processes happen, specifically, in the use of all fonts in the school context. The research was applied through questionnaires to teachers of the Novo Hamburgo/RS Municipal Education Network and, for the analysis of the produced data, the Bakhtian perspective on the teaching of the language was used reflexively, the legislation and guiding documents to base the defense of the guarantee of the literacy process in the social use of writing and reading.
\end{abstract}

Keywords: Handwriting. Literacy. Bakhtin. BNCC.

\section{Introdução}

O problema com as letras não se reduz ao princípio acrofônico. Historicamente, as pessoas foram modificando a forma gráfica das letras, criando, assim, outros alfabetos. Por causa de um princípio cumulativo, que todo sistema de escrita tem, resultou que, hoje, temos vários alfabetos em uso comum no dia a dia,

1

Professora na Rede Municipal de Ensino de Novo Hamburgo. Mestranda Profissional em Educação da UERGS. Novo Hamburgo/ Brasil. E-mail vanessa.trierweiler@gmail.com.

2

Doutora em Linguística Aplicada. Docente do Mestrado Profissional em Educação- UERGS. Bagé/ Brasil. Email veronice-silva@uergs.edu.br. 
como o das letras de forma maiúsculas, das letras minúsculas, das letras cursivas maiúsculas e minúsculas e uma infinidade de estilos ou fontes de letras, como se pode observar no mundo ao nosso redor. (CAGLIARI, 1989, p. 79)

No contexto educacional há frequentes questionamentos sobre o ensino e a aprendizagem da letra cursiva constar no currículo escolar. Até pouco tempo, a aprendizagem inicial da língua escrita passava pela cópia legível de todas as letras e, a partir de estudos e da legislação norteadora, entendeu-se a diferenciação entre aprendizagem da escrita e caligrafia.

Sendo a caligrafia uma atividade considerada obsoleta por muitos educadores, questionase sobre ensinar ou não o traçado da letra cursiva no processo de alfabetização, assim como ensinar ou não os outros tipos de letras. Observa-se, porém, que muitos estudantes, mesmo sem terem aprendido a dominar o traçado convencional e desejando escrever com letra cursiva, utilizam-na no contexto escolar e familiar, criando traçados próprios ao escreverem emendado, característica deste tipo de letra.

Entende-se que essa discussão pedagógica não pode mais ser protelada, uma vez que a Base Nacional Comum Curricular, homologada ao final de 2017, especifica e define o domínio das convenções gráficas (letras maiúsculas e minúsculas, cursiva e script) como capacidade/ habilidade da (de)codificação na alfabetização, que deve, ainda, consolidar-se nos dois primeiros anos do Ensino Fundamental. Traz também, no texto introdutório da área de Língua Portuguesa, a necessidade de que os estudantes conheçam o alfabeto e a mecânica da escrita e leitura e afirma que se considerará alfabetizado o sujeito que:

[...] consiga "codificar e decodificar" os sons da língua (fonemas) em material gráfico (grafemas ou letras), o que envolve o desenvolvimento de uma consciência fonológica (dos fonemas do português do Brasil e de sua organização em segmentos sonoros maiores como sílabas e palavras) e o conhecimento do alfabeto do português do Brasil em seus vários formatos (letras imprensa e cursiva, maiúsculas e minúsculas), além do estabelecimento de relações grafofônicas entre esses dois sistemas de materialização da língua. (BRASIL, 2017, p. 88)

Através de questionário aplicado a professores alfabetizadores da Rede Municipal de Ensino de Novo Hamburgo - RS (RME-NH), busca-se compreender sobre as divergências percebidas no discurso pedagógico informal destes docentes quanto ao uso, ou não, da letra 
cursiva no processo de ensino e aprendizagem, nos três primeiros anos do Ensino Fundamental ${ }^{3}$. As análises, embora restritas a uma determinada realidade, permitem estabelecer relações com discussões mais amplas sobre a temática.

Assim, este artigo, tem como objetivo geral reflexionar sobre o uso, o ensino e a aprendizagem da letra cursiva e os objetivos específicos são compreender como e se o ensino e a aprendizagem da letra cursiva ocorrem na RME-NH.

Para tanto, traz contribuições de autores que discutem especificamente essa temática, como Cagliari (1989), Massini-Cagliari (2004), Piccoli e Camini (2012). Também se embasa em documentos norteadores e legisladores, publicados na última década pelo Ministério da Educação, que orientam pedagogicamente sobre o uso dos diferentes tipos de letras no processo de alfabetização e definem as políticas de ensino e os direitos à aprendizagem dos estudantes do Ensino Fundamental.

Para refletir sobre como o uso das letras no processo de ensino e aprendizagem pode ou não fazer sentido para a criança que está em processo de alfabetização nos primeiros anos do Ensino Fundamental, o presente estudo busca em Bakhtin (1997, 1999, 2016) reflexões sobre a dinâmica social das práticas de leitura e escrita.

\section{A polêmica da letra cursiva na última década}

Atualmente, as instituições de ensino brasileiras sentem-se fragilizadas diante de práticas escolares que fracassam continuamente, permitindo que os sujeitos perpassem pela escola sem garantir sucesso na aprendizagem. Durante as últimas décadas, os diversos estudos realizados sobre o processo de aquisição da leitura e escrita, revelaram que os discursos orais e escritos do sujeito dizem mais sobre os processos de letramentos vivenciados por ele fora da escola, que sobre sua escolarização.

Os multiletramentos (ROJO; MOURA, 2012) aos quais é submetido o sujeito desde seu nascimento por estar em sociedade letrada, não sugerem a letra cursiva como essencial à aprendizagem. Em tempos midiáticos, a letra cursiva aparece pouco. As crianças interagem com

3

Conforme legislação vigente até 2017, o bloco pedagógico considerava os três primeiros anos do Ensino Fundamental. Com a BNCC homologada ao final de 2017 e sua implementação dada somente no início de 2020 , a pesquisa ainda considerou a consolidação da alfabetização até o final do $3^{\circ}$ ano. 


\section{Revista de Estudos Acadêmicos de Letras}

esta letra ao terem contato visual com alguns signos que representam marcas conhecidas mundialmente, como: Coca-Cola, Mellitta, Johnson e Johnson, Cavalera, Ray-Ban etc.

Em nossa sociedade atual, principalmente para adultos e idosos, a letra cursiva manuscrita é tida como referência ao gênero textual carta que, há poucas décadas, era a forma mais utilizada de comunicação entre familiares, amigos e amantes, sendo assim, romantizada no imaginário e na história. Atualmente, utiliza-se essa letra em gêneros textuais menos formais como bilhetes, listas, assinaturas e em convites, principalmente para casamentos, onde as maiúsculas cursivas são utilizadas, inclusive, para criação de monogramas dos noivos.

Muitos artigos em revistas voltadas ao público educador problematizam o ensino e a aprendizagem dos quatro tipos de letras existentes em nosso sistema de escrita, percebendo-se a defesa do uso no processo ensino e aprendizagem, pelo viés da neurociência e dos documentos legais; e a defesa da extinção da letra cursiva no processo ensino e aprendizagem, pelo viés da tecnologia e da memorização da caligrafia.

Assim, há teóricos e estudiosos da educação que consideram desnecessários o ensino e o uso da letra cursiva e, principalmente entre professores alfabetizadores e estudiosos da área, não há consenso sobre o ensino e a aprendizagem da letra cursiva. Um exemplo é o linguista Carlos Alberto Faraco (SCHWARTSMAN, 2010) que diz que a cursiva mantém-se por pura tradição e crítica: "E você sabe que a escola é cheia de mil regras sem qualquer sentido!".

A discussão sobre a minimização da importância da escrita à mão em razão do uso das tecnologias na educação é outra questão que os professores relatam como impeditiva para o ensino e a aprendizagem da letra cursiva no contexto escolar. Atualmente, as crianças desempenham a escrita e leitura de forma muito qualitativa no manuseio dos diferentes suportes tecnológicos atuais e a letra cursiva não aparece com frequência nesses meios. No entanto, sendo o Brasil um país continental, com realidades muito diferentes de norte a sul, não se pode acolher ainda, a ideia imediata de que todos terão acesso e poderão utilizar-se somente de smartphones e computadores para a leitura e a escrita.

$\mathrm{Na}$ revisita aos documentos e publicações pedagógicas orientadoras do Ministério da Educação para formação de professores de 2007, já se afirmava a importância do ensino e aprendizagem de todas as letras de nosso sistema de escrita, prescrevendo a necessidade dos 
estudantes fazerem "letra boa" e entendendo que a caligrafia legível continua sendo um objetivo a ser alcançado pela escola:

Especificamente quanto às funções da escrita cursiva, é importante o aluno saber que, além de representar estilos individuais de traçar as letras, ela também serve para se escrever com rapidez. Compreendendo os usos da escrita cursiva, os alunos poderão concluir que é possível escrever com a letra que quiserem quando fizerem anotações pessoais, mas que deverão procurar fazer "letra boa" quando forem escrever para outras pessoas. (BRASIL, 2007, p. 30)

O mesmo texto ainda destaca a importância e o papel do professor no ensino da caligrafia de todos os tipos de letras, explicando que para o leitor, é indispensável a capacidade de identificação das letras, distinguindo-as umas das outras e que, por isso, “[...] é necessária a capacidade motora de grafar devidamente cada letra. Conhecer o alfabeto também implica que o aluno compreenda que as letras variam na forma gráfica e no valor funcional” (BRASIL, 2007, p. 30).

Os autores Massini-Cagliari e Cagliari (2004) que dedicam artigos sobre o assunto defendem, também, que deve haver a intencionalidade pedagógica do professor quanto ao ensino de todos os tipos de letras:

Porque a letra é uma noção abstrata, é necessário um apoio externo para definir o que pertence a uma letra e, até mesmo, o que pertence ou não à escrita, excluindo outras formas gráficas. A simples identificação de sons e de letras correspondentes pode não ser suficiente para escrever e ler na sociedade [...]. (CAGLIARI \& MASSINI-CAGLIARI, 2004, p. 92)

Já no documento do MEC do Pacto Nacional pela Alfabetização na Idade Certa (PNAIC), encontrou-se a prescrição pedagógica da metodologia gradual de ensino sobre as letras de nosso sistema de escrita, especificando que no primeiro ano "[...] recomenda-se o uso de letras de imprensa maiúsculas, que por serem mais fáceis de reconhecer e de grafar, liberam o aprendiz para que ele se concentre nas questões conceituais" (BRASIL, 2012, p.17). No entanto, também

4

Nota da autora: importante ressaltar que quando se utiliza a expressão "letra boa" propaga-se um juízo de valor sobre uma determinada caligrafia ser melhor que outra. Entende-se que a expressão "letra legível" seria o suficiente para o profissional alfabetizador compreender que a orientação pedagógica para alfabetização deveria abranger também o ensino manuscrito de todos os tipos de letras. 
recomenda que, desde o primeiro ano, os estudantes devem ser expostos "[...] aos diferentes formatos que uma mesma letra pode assumir" (BRASIL, 2012, p.17), utilizando a cursiva e minúscula quando já tiverem construído a hipótese alfabética na escrita.

A opção da instituição escolar ou do professor em não ensinar a caligrafia dos quatro tipos de letras pode acarretar dificuldades na leitura de um traçado ilegível, conforme os autores Massini-Cagliari e Cagliari (2004, p. 91):

Em princípio, a tarefa de reconhecimento das letras registradas por outrem deveria ser fácil, sobretudo levando em conta a prática de escrita e de leitura. Mas, interessantemente, esta não é uma tarefa tão simples assim. Não raramente, precisamos verificar bem qual letra está escrita. Às vezes, precisamos mesmo começar adivinhando, para somente depois ter certeza. Essa tarefa tornou-se extremamente complicada e difícil, ao longo da história dos sistemas de escrita, com o uso das escritas cursivas, concatenadas e com idiossincrasias de todos os tipos. A questão do reconhecimento do símbolo escrito pode passar, inclusive, por questões culturais, de estilos gráficos, mais ou menos em moda, em determinada região geográfica.

O documento do MEC "Programa de formação continuada de professores dos anos/séries iniciais do Ensino Fundamental: alfabetização e linguagem” indica uma compreensão equivocada do construtivismo quanto à importância da aprendizagem das diferentes letras e relaciona essa má interpretação às dúvidas dos professores sobre a importância, ou não, do ensino e aprendizagem da letra cursiva:

Outra questão controversa diz respeito à oposição do construtivismo ao ensino meramente transmissivo, que limita o aluno a apenas memorizar e reproduzir conceitos e regras. O problema é que, em nome dessa crítica, algumas interpretações equivocadas do construtivismo têm recusado a apresentação de informações relevantes ao avanço dos alunos, como se todos os conhecimentos pertinentes à apropriação da língua escrita pudessem ser construídos pelos próprios alunos, sem a contribuição e a orientação de um adulto mais experiente. (BRASIL, 2007, p 30)

Embora haja muitas críticas sobre as concepções do construtivismo de Piaget (1984), entende-se que era defensor de uma escola ativa, onde o estudante não fosse considerado passivo e mero receptor do conhecimento, mas sujeito de saberes prévios que, através da interação construiria sua aprendizagem. Entende-se que, nessa escola ativa, o professor precisa observar e 
diagnosticar os saberes que cada sujeito traz e mediar propostas que desafiem e desequilibrem suas verdades, a fim de assimilar, acomodar e equilibrar novos conhecimentos.

Desta forma, devido a tantas opiniões e estudos controversos a respeito do ensino e aprendizagem dos quatro tipos de letras, essencialmente a letra cursiva, perguntou-se aos professores da RME-NH sobre a temática.

\subsection{Metodologia da pesquisa}

Para compreender a prática de ensino e aprendizagem nas turmas de alfabetização ${ }^{5}$ da RME-NH, aplicou-se a vinte professores alfabetizadores ${ }^{6}$ de sete escolas, um questionário contendo 17 questões, objetivas e descritivas, que abordavam o uso do alfabeto e do traçado dos diferentes tipos de letras no processo ensino e aprendizagem.

O questionário, enquanto técnica de investigação é definido por Gil (2014, p. 121) como “[ [...] um instrumento composto por um conjunto de questões que são submetidas a pessoas com o propósito de obter informações sobre conhecimentos, crenças, sentimentos, valores, interesses, expectativas, aspirações."

O questionário foi elaborado com perguntas abertas e fechadas, precedidas de um estudo teórico sobre o uso do alfabeto nas quatro letras existentes em nosso sistema de escrita brasileiro, sendo formulado pela pesquisadora com base na legislação vigente e, principalmente, com base nos objetivos da pesquisa.

Entende-se de suma importância descrever o perfil dos profissionais, uma vez que a concepção de cada um é questionada e relevante de acordo com o tempo em que alfabetiza e sua formação, pois conforme Tardif (2004, p. 103-104):

O professor não é somente um "sujeito epistêmico" que se coloca diante do mundo numa relação estrita de conhecimento [...] é um "sujeito existencial" no verdadeiro sentido da tradição fenomenológica e hermenêutica, isto é, um "serno-mundo" [...], uma pessoa completa com seu corpo, suas emoções, sua linguagem, seu relacionamento com os outros e consigo mesmo.

5

6

Considera-se o bloco pedagógico do $1^{\circ}$ ao $3^{\circ}$ ano do Ensino Fundamental.

O número de entrevistados representa $10 \%$ dos profissionais atuantes nesta RME atualmente. 
O ambiente de pesquisa é a Rede Municipal de Ensino de Novo Hamburgo (RME-NH) e os sujeitos de pesquisa são professores, do sexo feminino, e o perfil de formação das profissionais, bem como o tempo de atuação de cada uma na educação foram compilados em gráficos.

Assim, o gráfico 1 mostra que a grande maioria dos profissionais que responderam ao questionário possui Curso Normal (Magistério), somente um não é graduado em Pedagogia/ Licenciatura e, a maioria, possui Especialização na área da Educação. Percebe-se então que são profissionais com formação específica na educação e capacitados, teoricamente, para alfabetizar e compreender as concepções, metodologias e orientações legais referentes ao processo ensino e aprendizagem nos primeiros anos do Ensino Fundamental.

Gráfico 1 - Formação dos professores alfabetizadores da RME-NH



Fonte: Autora, 2018.

O gráfico 2 mostra o tempo de atuação destes professores na alfabetização que variam, de 1 ano a mais de 20 anos de experiência. Esse dado mostra que 45\% dos profissionais alfabetizadores desta rede de ensino teria, na prática, mais de dez anos de experiência, ou seja, tempo considerável e suficiente para sentirem-se seguros ao alfabetizar e opinar sobre a importância ou não do ensino e aprendizagem dos quatro tipos de letras existentes em nosso sistema de escrita.

Gráfico 2 - Tempo de atuação dos profissionais da RME-NH em turmas alfabetizadoras 


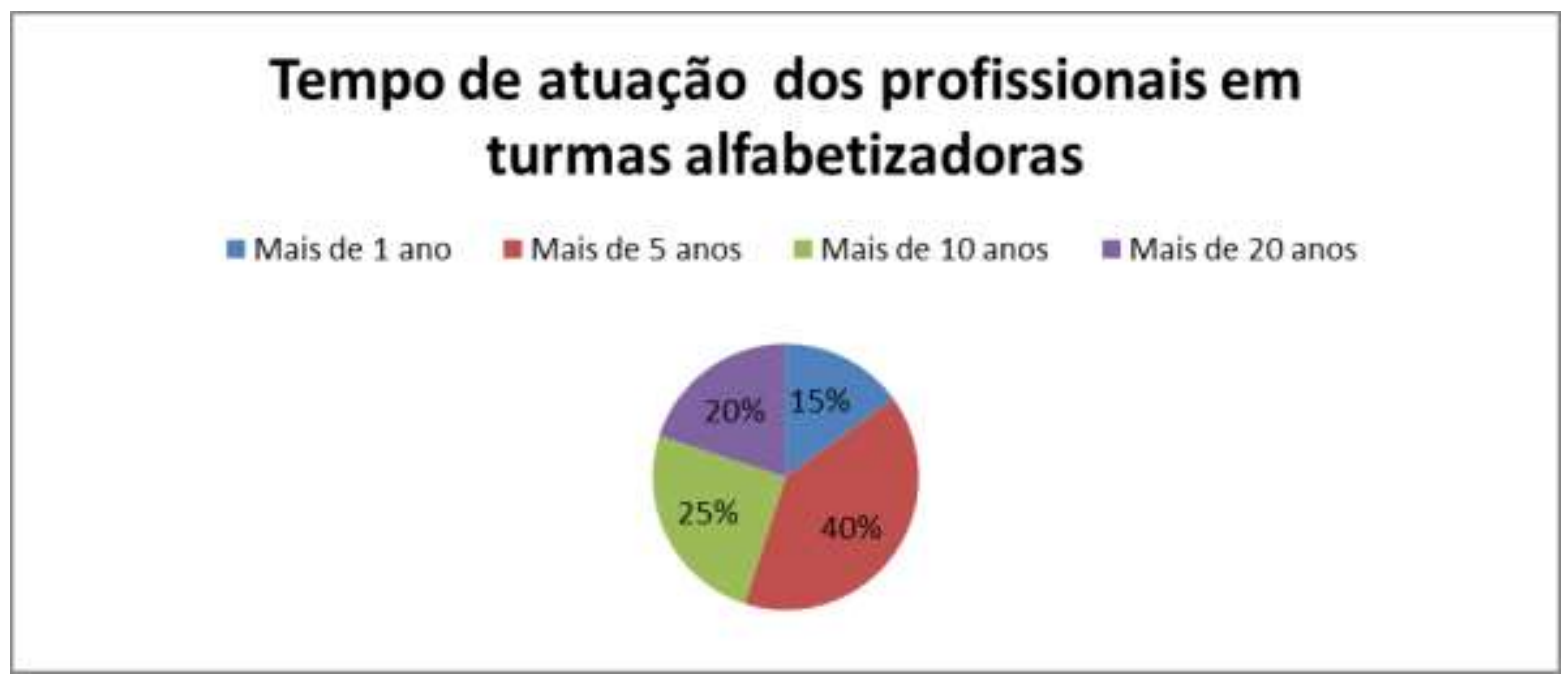

Fonte: Autora, 2018.

Sendo a pesquisadora colega dos sujeitos de pesquisa, salienta-se que a sensibilidade e a ética profissional foram balizadores na coleta do material analisado. O nome dos envolvidos não foi divulgado na pesquisa, dando-se a caracterização e descrição dos profissionais somente em nível de formação profissional e de tempo de experiência na alfabetização.

\subsection{Discussão teórica e resultados da pesquisa}

A BNCC (2017) traz como direito de aprendizagem os quatro tipos de letras existentes em nosso sistema de escrita. Se os letramentos representam maneiras sociais e culturais de se proceder por meio do uso de textos, destaca-se a importância dos professores pensarem sobre os tipos de letramentos que buscam produzir e construir a partir de suas escolhas teóricometodológicas.

Ao responderam ao questionário, todos os professores afirmaram que havia alfabeto em suas salas de aula e que os quatro tipos de letras estavam expostos, em alfabetos de diferentes materiais: EVA, papel, madeira, plástico e tecido. A grande maioria afirma que confecciona seus próprios alfabetos e utilizam papel e plástico para tal. O alfabeto móvel e interativo, em tapetes, peças, jogos também se faz presente em muitas salas.

Quanto à escolha das letras a serem expostas, a maioria dos professores respondeu que foi escolha da escola e do professor alfabetizador, em acordo mútuo, conforme o Projeto Político Pedagógico e os planos de estudos da série/ano. Ao serem questionados sobre quais letras, neste 


\section{Revista de Estudos Acadêmicos de Letras}

último trimestre do ano, o estudante reconhece, que letras ele lê e que letras usa para escrever, houve bastante divergência nas respostas, uma vez que os entrevistados atuam nos três primeiros anos do Ensino Fundamental. Os resultados apontam, no entanto, que ao final do $3^{\circ}$ ano, todos os estudantes reconhecem os quatro tipos de letras, leem (quando estão alfabéticos), mas que nem todos as escrevem.

Entende-se que cada criança tem seu processo de aprendizagem de forma única e o currículo deve ser adaptado e adequado de acordo com o sujeito. No entanto, se cada ano/ série tem objetivos e habilidades a serem desenvolvidos (BNCC, 2017) e o estudante deve estar alfabetizado ao final do $2^{\circ}$ ano, compreende-se que o ensino do traçado dos quatro tipos de letras deve ser abordado nestes dois primeiros anos do Ensino Fundamental, de forma que o uso social da escrita esteja imbricado no planejamento dos professores.

Esse diagnóstico, compilado dos questionários, aponta que, ao serem expostos e conhecedores dos diferentes tipos de letra, através do alfabeto em sala de aula e da leitura de gêneros textuais diversos nos quatro tipos de letras, os alunos reconhecem as letras e as leem. No entanto, não estando contemplada a caligrafia da letra cursiva no planejamento e não havendo uma metodologia para esse ensino, chega-se ao consenso de que os estudantes não conseguem traçá-la corretamente.

Bakhtin (1997) ressalta que a interação por meio da linguagem dar-se-á em contextos igualitários, onde a relação dialógica flua para todos os sujeitos envolvidos. Ao responderam que consideram importante a caligrafia e o ensino do traçado das letras, mas apontarem que a cursiva deva ser ensinada quando os alunos estiverem alfabéticos, entende-se que os profissionais alfabetizadores isentam-se deste ensino, uma vez que o processo de aprendizagem na alfabetização não é homogêneo e que, por vezes, é sabido que nem todos os estudantes cheguem ao nível alfabético ao final do ano.

Destacam-se algumas respostas colhidas dos questionários respondidos pelos professores, que justificam a importância do ensino do traçado das letras para os profissionais entrevistados: “[...] para que o aluno consiga fazê-lo corretamente"; “[...] é de extrema importância, sempre com o intuito de que entendam que escrevem para um leitor e, que este, precisa entender a mensagem"; “[...] faz parte do universo da alfabetização"; “[...] o ensino da caligrafia é uma habilidade psicomotora e a melhor forma de aprender é com a prática supervisionada pelo 
professor"; “[...] para que os alunos saibam como devem escrever. Se não apresentarmos para eles, como os mesmos saberão?".

Entendendo linguagem como interação (BAKHTIN, 1999) é de extrema relevância que as instituições escolares signifiquem a aprendizagem dentro de seu contexto social. É necessário que a língua seja ensinada de forma contextualizada, que seu uso tenha sentido. Assim, acredita-se que a abordagem da língua reflexiva deva ser vista através da perspectiva histórica e viva da língua, dentro de seu contexto de uso conforme diz Bakhtin (1998, p.146) "[...] justamente um conflito tenso no nosso interior pela supremacia dos diferentes pontos de vista verbais e ideológicos, aproximações, tendências, avaliações".

Usar a língua com autonomia consiste em conhecer seus diversos recursos expressivos de sentido, aplicando-os assertivamente em cada contexto sociocultural (BAKHTIN, 2016). Assim, ser autônomo é ser conhecedor de todas as formas de escrita de sua sociedade. Nesse sentido, Camini (2013, p. 30) contribui com a discussão ao sustentar que "Em vez de discutir a obsolescência da escrita à mão, é imperioso discutir o lugar necessário de cada uma dessas escritas - digital e manuscrita - nas aprendizagens escolares".

\section{Considerações finais}

A educação tem o compromisso político de ensinar a língua formal de nosso país, através de processos de letramentos que potencializem o discurso oral e escrito dos sujeitos, tornando-os protagonistas na sociedade em que vivem.

O desenvolvimento da capacidade do uso eficaz da linguagem relaciona-se a ações cotidianas, pessoais e profissionais, à busca de informações, ao exercício da reflexão. No entanto, a autonomia pedagógica curricular das instituições de ensino deve respeitar as leis que alicerçam o ensino e a aprendizagem em nosso país.

Sendo direito de aprendizagem de todos estudantes, conforme documentos orientadores e legisladores vigentes, o processo de ensino e aprendizagem da letra cursiva no contexto escolar deve acontecer com significado e sentido para todos.

Desta forma, o ensino de todas as letras pode ser inclusivo e processo de empoderamento do sujeito, uma vez que ignorar uma forma de escrita existente em nossa sociedade, o deixa alheio à decodificação e à leitura de certos textos que permeiam seu cotidiano. 


\section{REFERÊNCIAS}

BAKHTIN, Mikhael. Estética da criação verbal: Os gêneros do discurso. $2^{\mathrm{a} e d . ~ S a ̃ o ~ P a u l o: ~}$ Martins Fontes, 1997.

BAKHTIN, Mikhael (VOLOSHINOV). Marxismo e filosofia da linguagem: problemas fundamentais do método sociológico na ciência da linguagem. Trad. Michel Lahud e Yara Frateschi Vieira. 9 ed. São Paulo: Hucitec, 1999.

BAKHTIN, Mikhail. Os gêneros do discurso. Paulo Bezerra (Organização, Tradução, Posfácio e Notas); Notas da edição russa: Seguei Botcharov. São Paulo: Editora 34, 2016.

BRASIL. Ministério da Educação. Base Nacional Comum Curricular. Brasília: MEC, 2017.

$\begin{array}{llll}\text { Terceira } & \text { versão } & \text { revista. } & \text { Disponível }\end{array}$ http://basenacionalcomum.mec.gov.br/images/BNCC publicacao.pdf.

BRASIL. Ministério da Educação. Pacto nacional pela alfabetização na idade certa: a apropriação do sistema de escrita alfabética e a consolidação do processo de alfabetização - Ano 2, Unidade 3. Brasília: 2012.

BRASIL. Ministério da Educação. Programa de formação continuada de professores dos anos/séries iniciais do Ensino Fundamental: alfabetização e linguagem. MEC, Secretaria de Educação Básica: Brasília, 2007.

CAGLIARI, Luiz Carlos. Alfabetização e Lingüística. São Paulo: Scipione, 1989.

CAMINI, Patrícia. Das ortopedias (cali)gráficas: um estudo sobre modos de disciplinamento e normalização da escrita. Dissertação (Mestrado em Educação). Universidade Federal do Rio Grande do Sul. Porto Alegre, 2010.

CAMINI, Patrícia. Escrita à mão, letra cursiva e caligrafia. Presença Pedagógica, v.19, n.113, p.26-32, set/ out, 2013.

GIL, Antonio Carlos. Métodos e Técnicas de Pesquisa Social. 6 ed. São Paulo: Editora Atlas S.A, 2008.

MASSINI-CAGLIARI, Gladis; CAGLIARI, Luiz Carlos. Categorização gráfica e funcional na aquisição da escrita e da leitura em língua materna. Vol. 02 N. 01v, jan/jun 2004.

PIAGET, Jean. Para onde vai a educação? 8 ed. Rio de Janeiro: José Olímpio, 1984. PICOLLI, Luciana. Prática pedagógica nos processos de alfabetização e letramento: análises 
a partir dos campos da sociologia da linguagem [manuscrito]. Tese (Doutorado). Universidade Federal do Rio Grande do Sul. Porto Alegre, 2009.

PICOLLI, Luciana; CAMINI, Patricia. Práticas pedagógicas em alfabetização: espaço, tempo e corporeidade. Erechim: Edelbra, 2012.

ROJO, Roxane; MOURA, Eduardo (orgs.). Multiletramentos na escola. São Paulo: Parábola Editorial, 2012.

SCHWARTSMAN, Hélio. Entrevista realizada com Carlos Alberto Faraco. Ensino da letra cursiva para crianças em alfabetização divide a opinião de educadores. Entrevista em Jornal Folha de São Paulo. Artigo publicado em 17/05/2010. Disponível em https://www1.folha.uol.com.br/educacao/2010/05/736314-ensino-da-letra-cursiva-para-criancasem-alfabetizacao-divide-a-opiniao-de-educadores.shtml Acesso em 29 jul. 2019.

TARDIF, Maurice. Saberes Docentes e Formação Profissional. Petrópolis: Vozes, 2004. 